\title{
ZEB1 confers stem cell-like properties in breast cancer by targeting neurogenin-3
}

\author{
Chen Zhou ${ }^{1, *}$, Huimin Jiang ${ }^{1, *}$, Zhen Zhang ${ }^{1}$, Guomin Zhang ${ }^{1}$, Hang Wang ${ }^{1}$, \\ Quansheng Zhang ${ }^{2}$, Peiqing Sun ${ }^{3}$, Rong Xiang ${ }^{1}$ and Shuang Yang ${ }^{1}$ \\ ${ }^{1}$ Tianjin Key Laboratory of Tumor Microenvironment and Neurovascular Regulation, Medical School of Nankai University, \\ Tianjin 300071, China \\ ${ }^{2}$ Tianjin Key Laboratory of Organ Transplantation, Tianjin First Center Hospital, Tianjin 300192, China \\ ${ }^{3}$ Department of Cancer Biology, Wake Forest University School of Medicine, Winston-Salem, NC 27157, USA \\ *These authors have contributed equally to this work \\ Correspondence to: Shuang Yang, email: yangshuang@nankai.edu.cn \\ Keywords: breast cancer, neurogenin-3, stemness properties, tumor initiation, ZEB 1 \\ Received: December 29, $2016 \quad$ Accepted: March 20, $2017 \quad$ Published: April 13, 2017 \\ Copyright: Zhou et al. This is an open-access article distributed under the terms of the Creative Commons Attribution License 3.0 \\ (CC BY 3.0), which permits unrestricted use, distribution, and reproduction in any medium, provided the original author and source \\ are credited.
}

\section{ABSTRACT}

Cancer stem cells (CSCs) are a subpopulation of cancer cells believed to be implicated in cancer initiation, progression, and recurrence. Here, we report that ectopic expression of zinc finger E-box binding homeobox 1 protein (ZEB1) results in the acquisition of CSC properties by breast cancer cells, leading to tumor initiation and progression in vitro and in vivo. The neurogenin 3 gene ( $\mathrm{Ngn} 3$ ) is a bona fide target of ZEB1, and its repression is a key factor contributing to ZEB1-induced cancer cell stemness. ZEB1 suppressed $\mathbf{N g n} 3$ transcription by forming a ZEB1/DNA methyltransferase (DNMT)3B/histone deacetylase 1 (HDAC1) complex on the $\mathbf{N g n 3}$ promoter, leading to promoter hypermethylation and gene silencing. The rescue of $\mathbf{N g n 3}$ expression attenuated ZEB1-induced cancer stemness and symmetric CSC division. Immunohistological analysis of human breast cancer specimens revealed a strong inverse relationship between ZEB1 and NGN3 protein expression. Thus, our findings suggest ZEB1-mediated silencing of $\mathbf{N g n} 3$ is required for breast tumor initiation and maintenance. Targeted therapies against the ZEB1/Ngn3 axis may be highly valuable for the prevention and treatment of breast cancer.

\section{INTRODUCTION}

Although cancer stem cells (CSCs) constitute just a small fraction of the total tumor cell population, they are thought to be the main drivers of tumorigenesis and cancer recurrence $[1,2]$. There is evidence that CSC numbers correlate well with aggressive tumor growth [3, 4]; moreover, specific changes in the microenvironment may induce, through mutagenic events or epigenetic alterations, a CSC expansion that potentiates tumor progression $[5$, 6]. Current knowledge indicates that CSC properties may be largely determined by evolutionarily conserved mechanisms dictating cell polarity and asymmetric cell division. Normal CSCs usually undergo asymmetric cell division, giving rise to daughter cells with different characteristics. Thus, this process results in simultaneous differentiation and self-renewal, while maintaining the number of stem cells constant for tissue homeostasis [7]. Symmetric cell division, in contrast, generates only stem cells. Whereas the resulting expansion of the stem cell population could be useful for tissue regeneration under normal physiological conditions, the deregulation of asymmetric and/or symmetric division may, under pathogenic conditions, promote tumor initiation [8]. For example, loss of tumor suppressor genes such as the adenomatous polyposis coli gene (APC), often favors increased symmetric division of CSCs, potentially leading to tumorigenesis [9]. Therefore, understanding the complex regulatory network that interconnects cell polarity and cell fate is paramount to elucidate the role of 
CSCs in carcinogenesis and to effectively guide preventive and therapeutic efforts.

Zinc finger E-box binding homeobox 1 (ZEB1), a pivotal member of the zinc finger-homeodomain transcription factor family, importantly influences developmental and homeostatic cell fate decision in a broad range of tissues [10-12]. The overexpression of ZEB1, demonstrated in breast, colon, prostate, and pancreatic cancer [13-16], contributes to impaired cell adherence and polarity [17], induction of epithelial to mesenchymal transition (EMT) [18], and the acquisition of chemo- and radio-resistant phenotypes $[19,20]$. A growing body of evidence suggests that ZEB1 promotes the generation of breast CSCs [21-23]. For instance, elevated expression of ZEB1 predicts radiotherapy relapse in triple-negative breast cancer patients, in which the CSC population is enlarged [20]. Moreover, ectopic expression of ZEB1 in breast cancer is readily influenced by microenvironmental signals such as TGF- $\beta$, resulting in CSCs population expansion by non-CSCs to CSCs conversion and increased tumorigenesis [24]. Interestingly, ZEB1-related stemness properties have been shown to arise rather indirectly, through the transcriptional regulation of miRNAs such as miR-200 and miR-203 [18]. However, the cellular and molecular mechanisms downstream of ZEB1 that contribute to tumorigenesis remain largely obscure.

In this study, we provide evidence that ZEB1 promotes CSC self-renewal in vitro and in vivo, thus leading to increased breast cancer initiation and growth. By reduced representation bisulfite sequencing (RRBS) analysis, we identified neurogenin-3 (Ngn3) as a bona fide target of ZEB1 implicated in the acquisition of cancer cell stemness. ZEB1 represses Ngn3 transcription by recruiting DNA methyltransferase (DNMT)3B and histone deacetylase (HDAC) 1 to the $\mathrm{Ngn} 3$ promoter, thus resulting in DNA hypermethylation and the silencing of $\mathrm{Ngn3}$. We also demonstrated an inverse correlation between ZEB1 and NGN3 expression in human breast cancer specimens. Notably, rescuing $N g n 3$ expression significantly attenuated ZEB1-induced CSC self-renewal and stemness. Our data elucidates an important role for ZEB1/Ngn3 signaling in regulating stem cell fate and suggests a potential therapeutic target for ZEB1-overexpressing cancers.

\section{RESULTS}

\section{ZEB1 induces stemness properties in breast cancer cells}

To assess the influence of ZEB1 expression on breast cancer initiation in vivo, we performed extreme limiting dilution analysis to detect ZEB1-induced CSC frequencies. To this end, ZEB1 gain-of-function transfection was performed in MDA-MB-231 breast cancer cells to establish a nude mouse xenograft model (Supplementary Figure 1A). Compared with control (Ctrl/231) tumor cells, ZEB1/231 tumor cells displayed a 32.8-fold increase in CSC frequency
(Figure 1A and Supplementary Figure 1B). Flow cytometry and immunohistochemical staining analysis further revealed increased activity of ALDH, a malignant human mammary stem cell marker [21], in tumors from ZEB1/231 xenografts (Figure 1B and Supplementary Figure 1C). In addition, measurement of the $\mathrm{CD} 44^{+} \mathrm{CD} 24^{-}$breast $\mathrm{CSC}$ population also demonstrated that ectopic expression of ZEB1 led to increased stemness properties in xenografted MDAMB-231 breast cancer cells (Figure 1C).

Next, by measuring three well-established CSC endpoints, i.e. tumorsphere formation, side population (SP) percentage, and stemness-related gene expression, we conducted in vitro studies to confirm that ZEB1 targets, in fact, breast CSCs. Our results demonstrated that ectopic ZEB1 expression in MDA-MB-231 cells increased tumorsphere formation (Figure 1D), SP percentage (Figure $1 \mathrm{E})$, and the expression of pluripotency markers such as NANOG, OCT4, and SOX2 (Figure 1F).

Additionally, we explored the effect of ZEB1 on CSC polarity during division by assessing, shortly after mitosis, the subcellular distribution of NUMB, a protein involved in cell fate specification [25]. To this end, cell division symmetry was evaluated in ZEB1/231 and $\mathrm{Ctrl} / 231$ cells treated with blebbistatin, a cytokinesis-arresting small molecule that induces formation of binucleated cells (Figure $1 \mathrm{G})$. Results showed that CD44 expression was abolished in up to $64.7 \%$ of mitotic $\mathrm{Ctrl} / 231$ cells, while NUMB was uniformly distributed around the actin cortex (Figure $1 \mathrm{G}$ and $1 \mathrm{H}$ ), suggesting that both daughter cells lost their stem cell identity upon symmetric cell division (symmetric commitment [SC]). In $27.3 \%$ of the Ctrl/231 cells, CD44 and NUMB were asymmetrically distributed [asymmetric division [AD]), wherein NUMB was present only in CD44progeny, but not in $\mathrm{CD}_{4} 4^{+}$, stem cell-like cells (Figure $1 \mathrm{G}$ and $1 \mathrm{H}$ ). In up to $8.0 \%$ of the binucleated $\mathrm{Ctrl} / 231$ cells, on the other hand, CD44 expression was symmetric, and NUMB showed a uniform distribution, thus manifesting a symmetric division (SD) phenotype. Interestingly, as shown in Figure 1H, this SD phenotype was substantially enhanced after ectopic expression of ZEB1 (8.0\% to $32.1 \%)$. In contrast, ZEB1 depletion achieved the opposite effect, i.e. reduced cancer stem-like cell properties (Supplementary Figure 2). These observations were not unique to MDAMB-231 cells; ZEB1 overexpression or depletion in SUM159 cells also resulted in enhanced and reduced CSC phenotypes, respectively (Supplementary Figure 3 and 4). In addition to the results from the previous study indicating that ZEB1 is capable of inducing EMT [26], the present data also suggest that ZEB1 is crucial for the acquisition or conservation of stemness properties in breast CSCs.

\section{ZEB1 downregulates Ngn3 via promoter hypermethylation}

Based on mounting evidence implying a contribution of ZEB1 to epigenetic regulation during tumorigenesis [27], we performed RRBS to identify endogenous targets 


\begin{tabular}{ccc}
\hline Injected cell no. & Ctri/231 & ZEB $1 / 231$ \\
\hline $2.0 \times 10^{6}$ & $5 / 5$ & $5 / 5$ \\
$1.0 \times 10^{6}$ & $4 / 5$ & $6 / 5$ \\
$5.0 \times 10^{5}$ & $3 / 5$ & $4 / 5$ \\
$2.5 \times 10^{5}$ & $2 / 5$ & $4 / 5$ \\
$1.25 \times 10^{5}$ & $1 / 5$ & $4 / 5$ \\
Estimated CSC frequency & $1 / 5542161$ & $1 / 169004$ \\
\hline Chisq $=6.68, P=0.0097$ & &
\end{tabular}

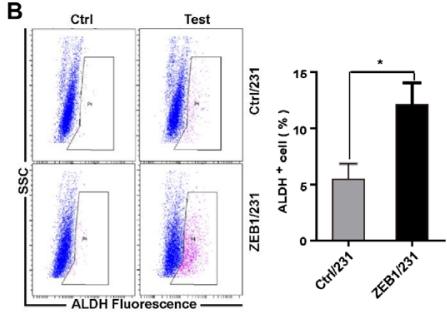

C

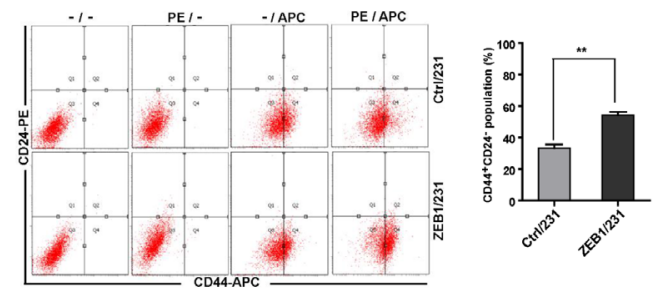

D
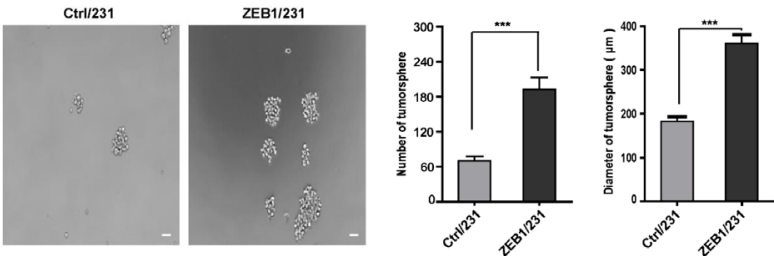

E
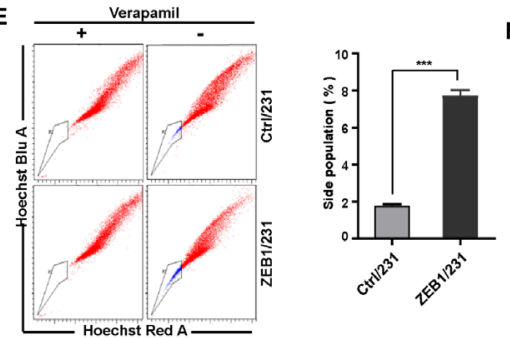
Ctrl $\frac{\text { ZEB1 }}{48 \mathrm{~h} 72 \mathrm{~h}}$

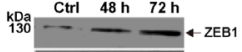
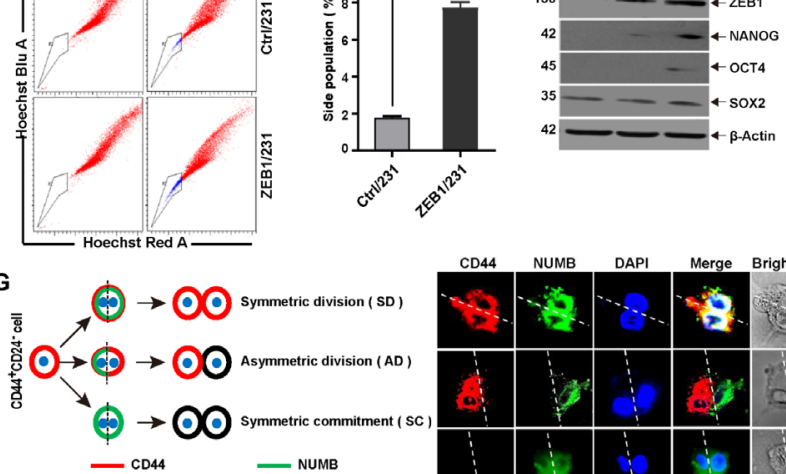

H
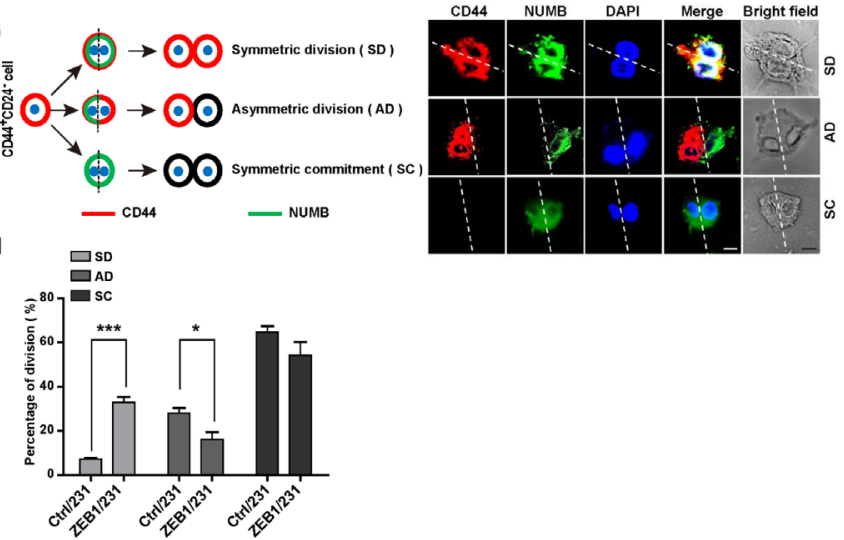

Figure 1: ZEB1 induces stemness properties in breast cancer cells. (A) For in vivo limited dilution assays, a total of $2 \times 10^{6}$, $1.0 \times 10^{6}, 5 \times 10^{5}, 2.5 \times 10^{5}$, and $1.25 \times 10^{5} \mathrm{ZEB} 1 / 231$ or Ctrl/231 cells were injected into the mammary fat pads of nude mice. After 15 days, the mice were euthanized, and estimated CSC frequency was analyzed using ELDA software. Data were analyzed with chi-square tests $\left({ }^{*} P=0.097\right)$. (B) and $(\mathbf{C})$ Tumor tissues were prepared in single-cell suspension and processed for ALDH activity (B) and CD44 ${ }^{+} \mathrm{CD} 24$ population (C) analysis by flow cytometry. ${ }^{*} P<0.05,{ }^{*} P<0.01$ vs. the respective control by Student's $t$-test. (D) ZEB1/231 or Ctrl/231 cells were prepared in single-cell suspension and seeded in 24-well ultra-low attachment plates at 1,000 cells/well. Tumorsphere formation was examined after 14 days of culturing. $* * * P<0.001$ vs. the respective control by Student's $t$-test. (E) ZEB1/231 or Ctrl/231 cells were stained with Hoechst 33342 in the presence or absence of verapamil. The side population fraction was examined by flow cytometry. $*_{* *} P<0.001$ vs. the respective control by Student's $t$-test. (F) The full-length ZEB1 expression plasmid was introduced into MDAMB-231 cells. At the indicated time points, the expression of ZEB1, NANOG, OCT4, and SOX2 was assessed by immunoblotting and was normalized to the levels of $\beta$-Actin. (G) Schematic showing SD, AD, and SC patterns. (H) Confocal fluorescence images showing CD44 (red) and NUMB (green) intracellular distribution during the first cell division of the CD44 ${ }^{+} \mathrm{CD} 24^{-}$population isolated from ZEB1/231 and $\mathrm{Ctrl} / 231$ cells and cultured in suspension with blebbistatin treatment. The percentage of the SD versus AD populations was analyzed. $* P<0.05, * * * P<0.001$ vs. the respective control by Student's $t$-test. Scale bars: $20 \mu \mathrm{m}$. 
A

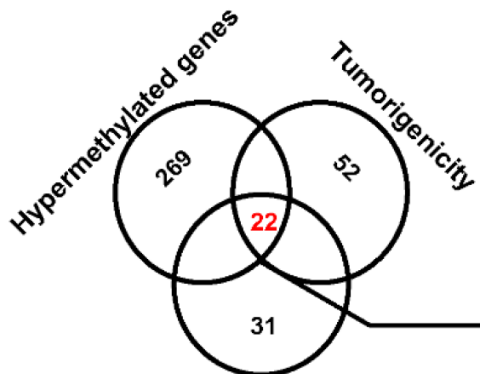

$E_{2}$ - box motif in promoter

C

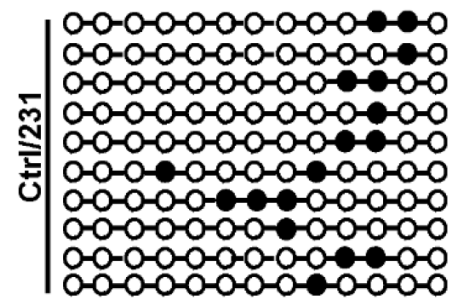

- Unmethylated

D

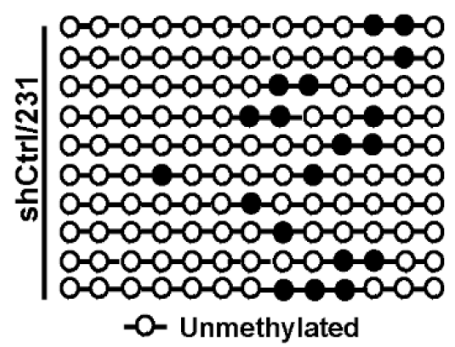

-0 - Unmethylated

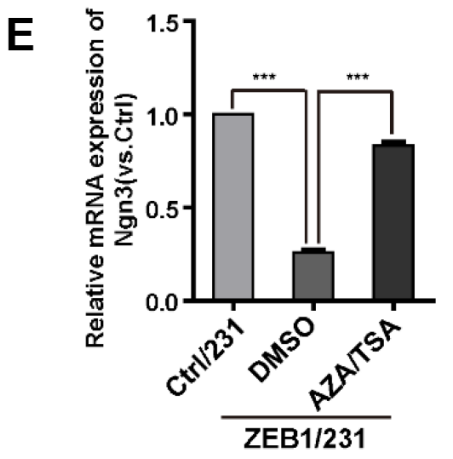

B
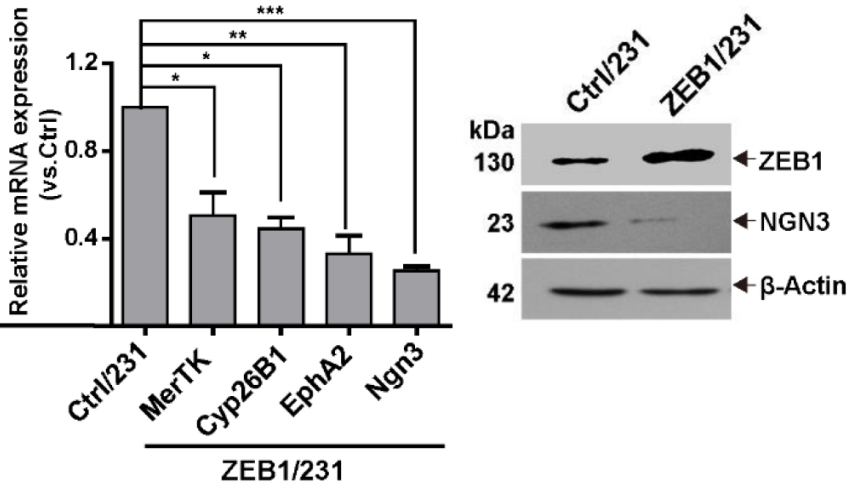

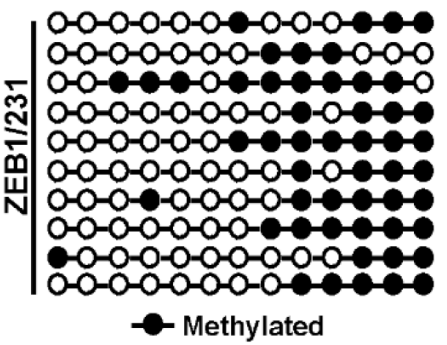

Methylated
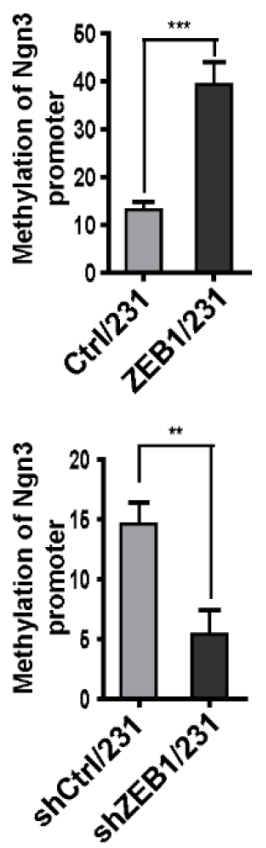

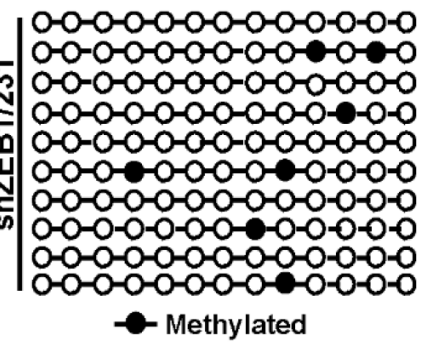

$\mathbf{F}$<smiles>[13CH3][13CH2]CCCF</smiles>

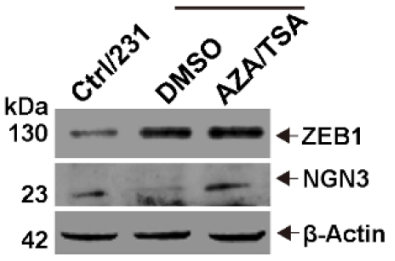

Figure 2: The Ngn3 promoter is a bona fide hypermethylation target of ZEB1. (A) Schematic representation of RRBS identification of the putative ZEB1 targets involved in breast tumorigenesis. Quantitative PCR were performed to verify the downregulation of MerTK, Cyp26B1, EphA2, and Ngn3 expression in ZEB1/231 vs. Ctrl/231 cells. $* P<0.05, * * P<0.01, * * * P<0.001$ vs. the respective control by Student's $t$-test. (B) The downregulation of NGN3 protein expression was assessed by immunoblotting in ZEB1/231 vs. Ctrl/231 cells and normalized to the levels of $\beta$-Actin. (C) and (D) The percentage of DNA methylation of the Ngn3 promoter was determined by BSP in ZEB1/231 vs. Ctrl/231 cells (C) and in shZEB1/231 vs. shCtrl/231 cells (D). $* * P<0.01, * * * P<0.001$ vs. the respective control by Student's $t$-test. (E) and (F) ZEB1/231 and Ctrl/231 cells were treated with AZA $(1.5 \mu \mathrm{M})$ and TSA $(2 \mathrm{mM})$ for the indicated time points. The expression of $N g n 3$ was assessed by quantitative PCR (E) and immunoblotting (F) and normalized to the levels of $\beta$-Actin. *** $P<$ 0.001 vs. the respective control by Student's $t$-test. 
of ZEB1 in MDA-MB-231 cells. We identified 291 genes containing differentially methylated regions (DMRs) in ZEB1/231 cells, as compared with Ctrl/231 cells. 22 of these genes possess potential tumorigenic functions and contain $\mathrm{E}_{2}$-box motifs for ZEB1 binding in their promoter regions (Figure $2 \mathrm{~A}$ ). We then performed quantitative PCR to determine the correlation between ZEB1 and these differentially methylated genes in ZEB1/231 cells. The results showed that ectopic ZEB1 expression significantly downregulated the mRNA levels of MerTK (c-mer protooncogene tyrosine kinase), Cyp26B1 (Cytochrome P450 26B1), EphA2 (ephrin type-A receptor 2), and Ngn3
(Figure 2A). Considering that Ngn3 influences stem cell properties and cell differentiation [28], immunoblotting was performed to verify that a negative correlation existed between ZEB1 and NGN3 protein expression (Figure 2B). Thus, these data indicate that ZEB1 promotes CSC renewal through repression of $\mathrm{Ngn} 3$ expression.

To further confirm that the inhibition of $\mathrm{Ngn3}$ expression by ZEB1 in breast cancer is correlated with DNA methylation, we conducted bisulfite sequencing PCR (BSP) to evaluate the methylation status of $13 \mathrm{CpG}$ residues in the 243-bp DMR region $(-164 /+79)$ of the Ngn3 promoter (Supplementary Figure 5A). Relative to
A

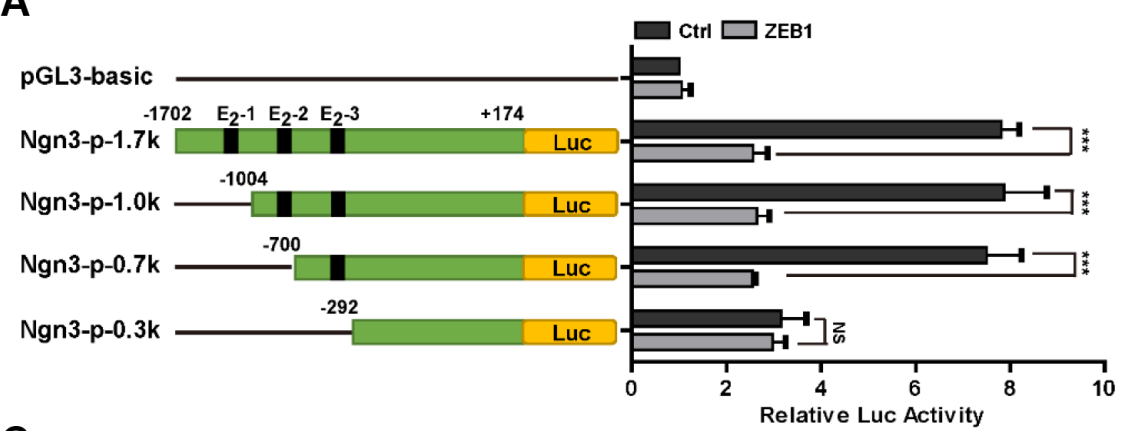

C

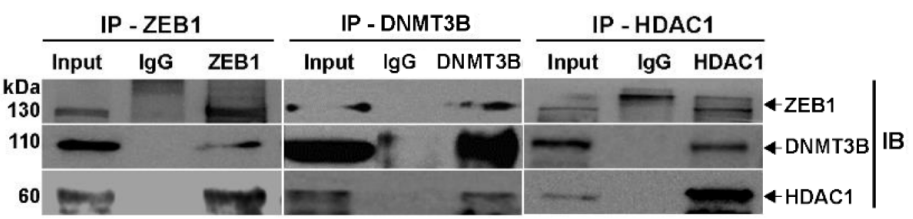

$\mathbf{F}$

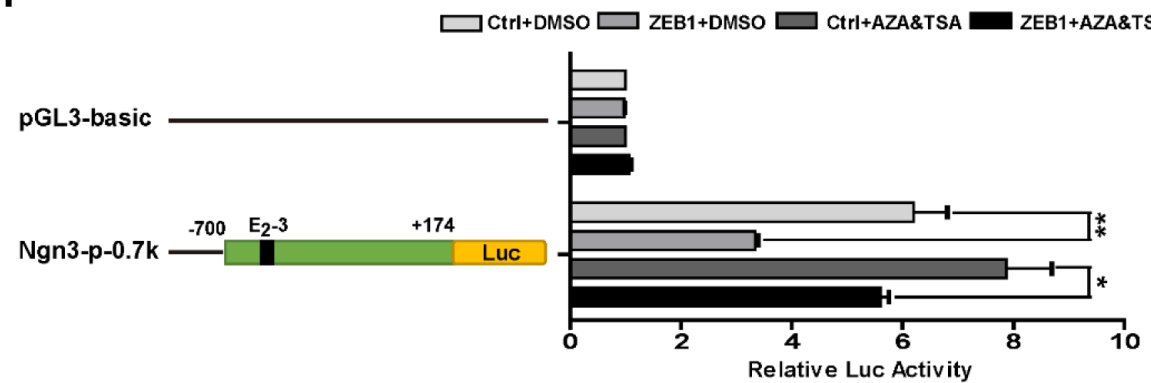

B

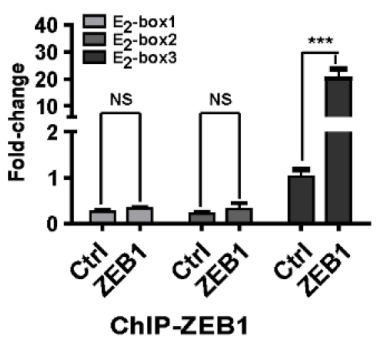

D

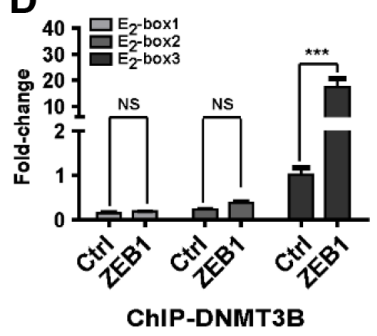

$E$

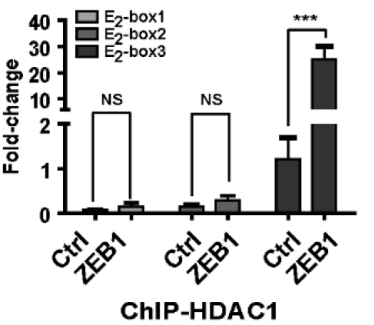

Figure 3: ZEB1 represses Ngn3 transcription via interaction with DNMT3B and HDAC1. (A) MDA-MB-231 cells were co-transfected with the ZEB1 expression plasmid and different wild-type or truncated Ngn3 promoter luciferase reporter constructs. Cell extract luciferase activities were determined $36 \mathrm{~h}$ after transfection using a Betascope analyzer. Luciferase values were normalized to Renilla activities. ${ }^{* * *} P<0.001$ vs. the respective control by Student's $t$-test. (B) The overexpression of ZEB1 significantly enhanced its recruitment to the endogenous $N g n 3$ promoter, as confirmed by a quantitative ChIP assay using $\mathrm{E}_{2}$-box-specific primers. ${ }^{* * *} P<0.001$ vs. the respective control by Student's $t$-test. (C) The interactions among ZEB1, DNMT3B, and HDAC1 protein were analyzed by coimmunoprecipitation in ZEB1/231 cells. (D) and (E) ZEB1 overexpression significantly enhanced the recruitment of DNMT3B (D) and HDAC1 (E) to the endogenous Ngn3 promoter, as confirmed by a quantitative ChIP assay using $\mathrm{E}_{2}$-box-specific primers. $* * * P<0.001$ vs. the respective control by Student's $t$-test. (F) MDA-MB-231 cells were co-transfected with the Ngn3-p-0.7k reporter and the ZEB1 expression plasmid, and then treated with AZA and TSA. Cell extract luciferase activities were determined $36 \mathrm{~h}$ after transfection using a Betascope analyzer. Luciferase values were normalized to Renilla activities. ${ }^{*} P<0.05,{ }^{*} P<0.01$ vs. the respective control by Student's $t$-test. 
Ctrl/231, DNA methylation was increased in ZEB1/231 cells (Figure 2C and Supplementary Figure 5B), while ZEB1 knockdown correlated instead with decreased DNA methylation (Figure 2D and Supplementary Figure 5C). Ngn3 mRNA expression was then compared by quantitative PCR in Ctrl/231 vs. ZEB1/231 cells and in shCtrl/231 vs. shZEB1/231 cells (Supplementary Figure $5 \mathrm{D}$ and $5 \mathrm{E}$ ), confirming a negative regulation of $\mathrm{Ngn} 3$ expression by ZEB1.

Gene regulation via promoter methylation is sometimes accompanied by an increase in the activities of DNMT and HDAC [29]. Thus, ZEB1/231 cells were treated with the demethylating agent 5-aza-2'deoxycytidine (AZA) and the HDAC inhibitor trichostatin A (TSA). These treatments significantly abolished ZEB1mediated downregulation of $\mathrm{Ngn3}$ at the mRNA and protein levels (Figure 2E and $2 \mathrm{~F}$ ). We also examined ZEB1-regulated promoter methylation of Ngn3 in SUM159 cells and obtained similar results (Supplementary Figure 6).

\section{ZEB1 represses Ngn3 transcription by recruiting HDAC1 and DNMT3B to its promoter}

Next, we performed promoter-reporter assays to elucidate the molecular mechanism by which ZEB1 regulates Ngn3 transcription. As shown in Figure 3A, the wild-type $-1702 /+174$ promoter of the $N g n 3$ gene has three canonical $\mathrm{E}_{2}$-box elements $[\mathrm{CA}(\mathrm{G} / \mathrm{C})(\mathrm{G} / \mathrm{C}) \mathrm{TG}]$ at positions $-1308 /-1303,-803 /-798$ and $-517 /-512$, to which ZEB1 may potentially bind [30]. The luciferase assay results indicated that ZEB1 overexpression decreased the promoter activity of the $N g n 3-\mathrm{p}-1.7 \mathrm{k}$ reporter by approximately $68 \%$ relative to control MDA-MB-231 cells without ZEB1 transfection (Figure 3A). A series of truncated Ngn3 promoter-reporter constructs were then generated for analysis. The luciferase assays showed that the deletion of the $-1702 /-700$ fragment, containing $\mathrm{E}_{2}-$ box-1 and -2, did not affect ZEB1-mediated repression of Ngn3 promoter activity. However, this transcriptional repression was eliminated after simultaneous deletion of all three $\mathrm{E}_{2}$-box elements. Importantly, quantitative ChIP assays indicated that ZEB1 overexpression resulted in a 20 -fold increase in its binding to the area of $\mathrm{E}_{2}-\mathrm{box}-3$, whereas the recruitment of ZEB1 to $\mathrm{E}_{2}-$ box-1 and -2 was less evident (Figure 3B and Supplementary Figure 7). These observations suggest a predominant role of the $\mathrm{E}_{2}-$ box-3 element in the regulation of $N g n 3$ transcription by ZEB1.

DNMT3B and HDAC1 have been shown to mediate the epigenetic regulatory functions of ZEB1 by acting as its cofactors [27]. We therefore performed co-immunoprecipitation experiments, which proved the interaction between ZEB1 and DNMT3B/HDAC1 in ZEB1/231 cells (Figure 3C). ChIP experiments further revealed that both DNMT3B and HDAC1 were recruited to the Ngn3 promoter in an $\mathrm{E}_{2}$-box-3-dependent manner, and the association was further increased by ZEB1 overexpression (Figure 3D and 3E). Next, the ZEB1 expression plasmid and an Ngn3 promoter construct containing $\mathrm{E}_{2}$-box-3 were introduced into MDA-MB-231 cells, followed by treatment with AZA and TSA. Luciferase assay results showed that exposure to AZA and TSA significantly attenuated ZEB1-mediated repression of Ngn3 promoter activity (Figure $3 \mathrm{~F}$ ). These observations highlight the importance of the $\mathrm{E}_{2}$-box elements, especially $\mathrm{E}_{2}$-box-3, in the regulation of $N g n 3$ expression by ZEB1 via interaction with DNMT3B and HDAC1.

\section{ZEB1 confers breast CSC properties by targeting Ngn3}

Next, we tested whether ZEB1/Ngn3 signaling would functionally alter the stemness properties of MDA-MB-231 cells. Thus, a control- or Ngn3-expressing plasmid was introduced into ZEB1/231 cells. Rescue of Ngn3 expression was assessed by immunoblotting (Figure 4A). Measurements of tumorsphere formation, SP percentage, $\mathrm{CD} 44^{+} \mathrm{CD} 24^{-}$breast CSC population, ALDH activity, and expression analysis of pluripotency genes demonstrated that ectopic ZEB1 expression led to increased stemness properties, whereas these changes were significantly attenuated by re-expression of Ngn3 (Figure 4A-4E). Notably, as shown in Figure 4F, we observed that the SD phenotype was less represented (32.0\% vs $13.3 \%)$, and the AD phenotype was enhanced (17.0\% vs $31.3 \%)$, after ectopic expression of Ngn3 in ZEB1/231 cells; this demonstrated that ZEB1 is linked to stem cell identity in breast cancer cells, thus at least partially accounting for the downregulation of $N g n 3$ expression. We also examined the involvement of Ngn3 in ZEB1-regulated cancer cell stemness properties in SUM-159 cells, with similar results (Supplementary Figure 8).

\section{Ngn3 is required for the induction of ZEB1- mediated CSC properties in vivo}

Consequently, we tested whether ZEB1-regulated Ngn3 expression would alter breast CSC frequencies in vivo. To do so, re-expression of Ngn3 was performed in ZEB1/231 cells to establish a nude mouse xenograft model. The results of the extreme limiting dilution assay showed that rescuing Ngn3 expression in ZEB1/231 tumors significantly attenuated CSC frequency (Figure 5A and Supplementary Figure 9). Immunohistochemical staining and flow cytometry analysis further revealed that the increases observed in both ALDH activity and the CD $44^{+}$CD24- $4^{-}$SC subpopulation in ZEB1/231 tumors were significantly abolished after re-expression of $\mathrm{Ngn3}$ (Figure 5B to 5D). Altogether, these data suggest that Ngn3 is a ZEB1 target that may be functionally implicated in the acquisition of stem cell characteristics. 


\section{Differential correlation of ZEB1 with NGN3 and ALDH1 expression in breast cancer specimens}

To further strengthen the pathological correlation between ZEB1/Ngn3 expression and breast cancer cell stemness, we performed immunohistochemical staining for ZEB1, NGN3 and ALDH1 in 156 primary breast carcinoma patient specimens. As shown in Figure 6A, the subjects were divided into three groups on the basis of their ZEB1 expression scores. The results indicated a strong negative correlation between the expression of ZEB1 and NGN3 (Figure 6A and 6B). Importantly, in tumors with high ALDH1 activity, we observed increased expression of ZEB1 and decreased expression of NGN3 (Figure 6C and 6D), strongly suggesting that dysregulated ZEB1/NGN3 signaling is functionally linked to tumor stem cell traits in breast cancer.
A

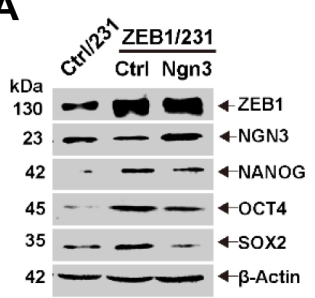

C

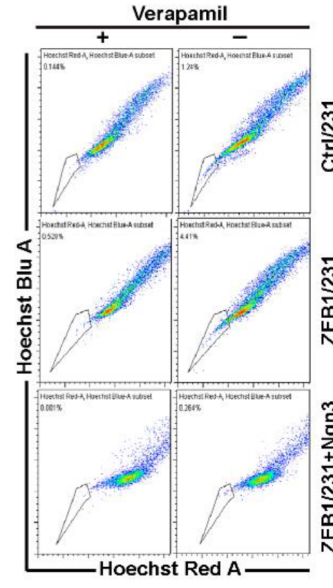

E

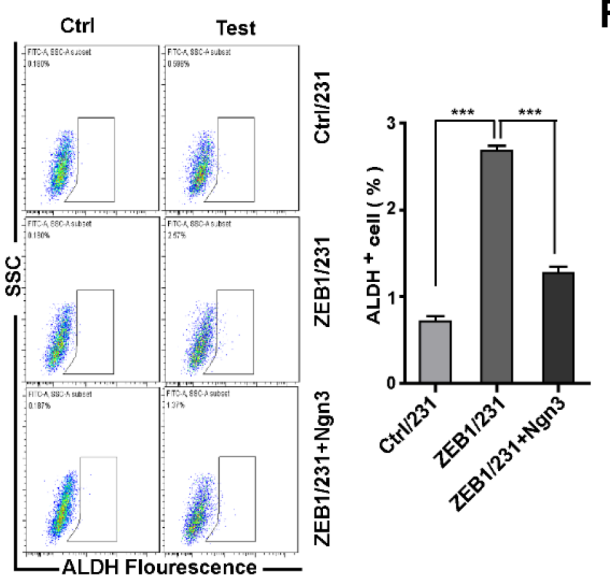

D
B

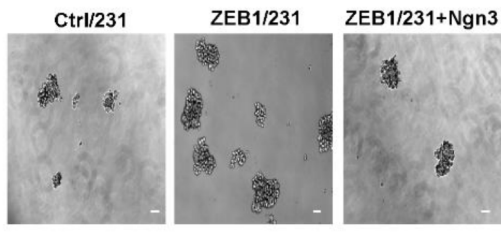

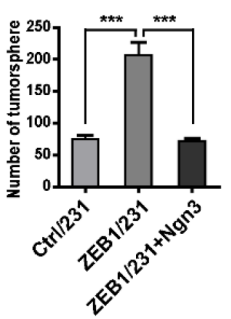

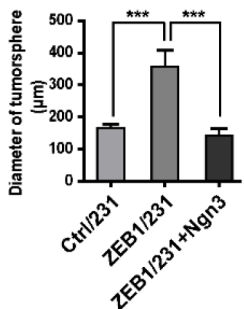

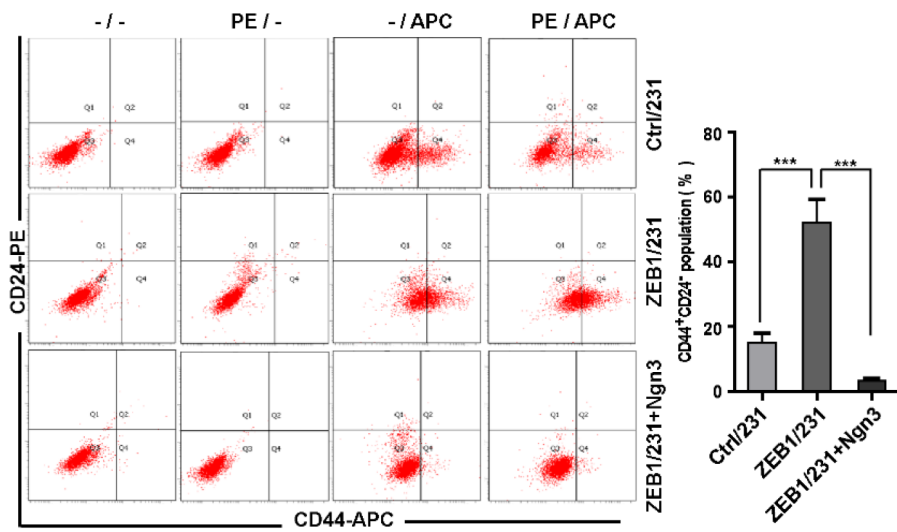

$\mathbf{F}$

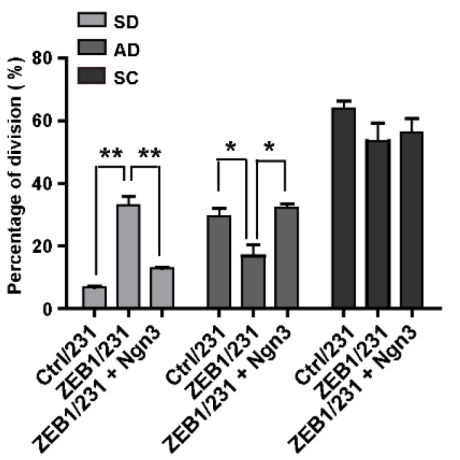

Figure 4: ZEB1/Ngn3 signaling affects breast CSC properties in vitro. (A) ZEB1/231 cells were transfected with an Ngn3 expression plasmid. The expression of ZEB1, NGN3, NANOG, OCT4, and SOX2 was assessed by immunoblotting and normalized to the levels of $\beta$-Actin. (B) to (F) Ngn3-mediated ZEB1 regulation of CSC properties was determined by analyzing tumorsphere formation (B), side population (C), CD44 ${ }^{+} \mathrm{CD} 24$ population (D), ALDH activity (E), and SD population frequency (F). ${ }^{*} P<0.05,{ }^{*} P<0.01$, ***P<0.001 vs. the respective control by Student's $t$-test. 
We also assessed ZEB1 and NGN3 co-expression in tumors with different grades. The results revealed that ZEB1 expression was relatively lower (Figure 6E), while NGN3 expression was higher (Figure 6F) in low-grade tumors, a result consistent with findings from a previous report showing that cancer stem cells are enriched in highgrade tumors [25].

\section{DISCUSSION}

The presence of radiation- and chemotherapyresistant breast CSC populations contributing to tumor growth by promoting angiogenesis, tissue invasion, and metastasis is supported by multiple evidence. Therefore, the elucidation of molecular regulators of breast CSCs

\section{A}

\begin{tabular}{cccc}
\hline Injected cell no. & Ctrl/231 & ZEB1/231 & ZEB1/231+Ngn3 \\
\hline $2.0 \times 10^{6}$ & $4 / 5$ & $4 / 5$ & $3 / 5$ \\
$1.0 \times 10^{6}$ & $3 / 5$ & $4 / 5$ & $3 / 5$ \\
$5.0 \times 10^{5}$ & $2 / 5$ & $4 / 5$ & $2 / 5$ \\
$2.5 \times 10^{5}$ & $2 / 5$ & $4 / 5$ & $0 / 5$ \\
$1.25 \times 10^{5}$ & $0 / 5$ & $3 / 5$ & $0 / 5$ \\
Estimated CSC frequency & $1 / 1059464$ & $1 / 444332$ & $1 / 1703863$ \\
\hline
\end{tabular}

B
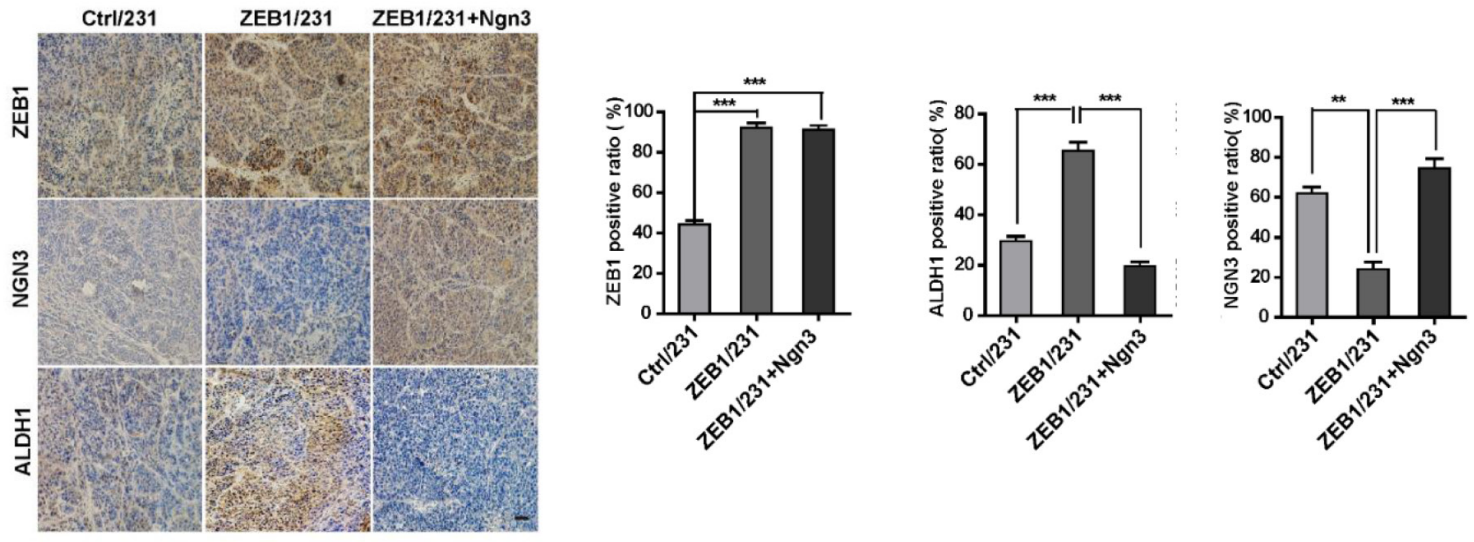

C

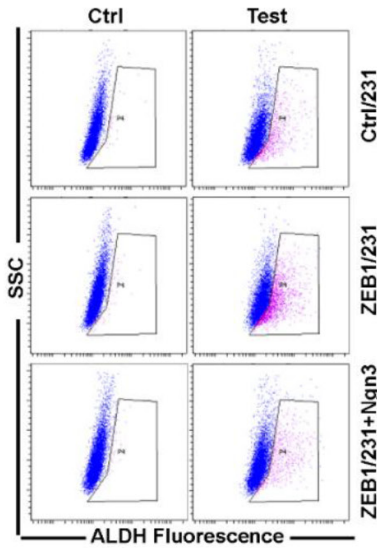

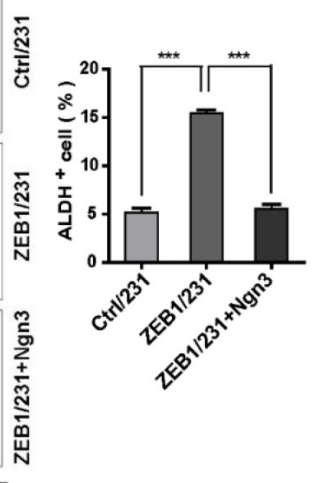

D

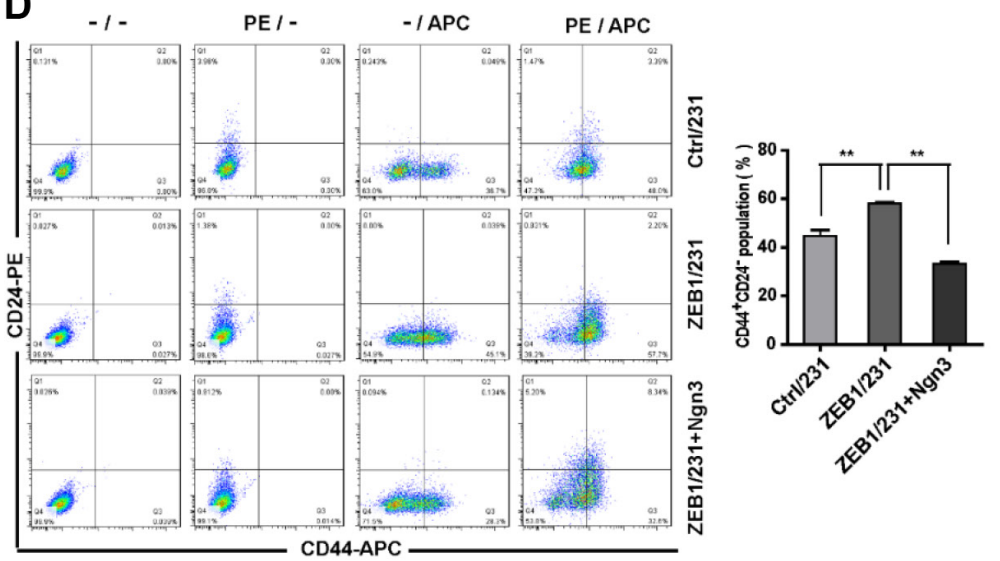

Figure 5: ZEB1/Ngn3 signaling affect breast CSC properties in vivo. (A) A total of $2 \times 10^{6}, 1.0 \times 10^{6}, 5 \times 10^{5}, 2.5 \times 10^{5}$, and $1.25 \times 10^{5}$ ZEB1/231 cells with or without Ngn3 re-expression were injected into the mammary fat pads of nude mice. After 15 days, the mice were euthanized, and the estimated CSC frequency was analyzed using ELDA software. Data were analyzed with chi-square tests $(* P=0.0063)$. (B) The expression of ZEB1, NGN3, and ALDH1 in breast cancer xenografts was examined by immunohistochemical staining. Scale bars, $50 \mu \mathrm{m} .{ }^{*} P<0.01, * * * P<0.001$ vs respective control in Student's $t$-test. (C) and (D) Tumor tissues were prepared in single-cell suspension and processed for ALDH activity (C) and $\mathrm{CD} 44^{+} \mathrm{CD} 24$ population (D) analysis by flow cytometry. $* * P<0.01, * * * P<0.001$ vs. the respective control by Student's $t$-test. 
may translate into improved anti-neoplastic therapies. Considering our findings, we propose that ZEB1 is a key regulator of breast CSCs and may be critically involved in tumor initiation. First, we showed that ZEB1 is required for tumor initiation and expression of stemness markers in vitro and in vivo, and this effect is Ngn3-dependent. Second, we found that ZEB1 interacts with DNMT3B and HDAC1 at the Ngn3 promoter, thus leading to DNA hypermethylation and downregulation of $N g n 3$ expression. Third, data from in vitro and in vivo models revealed that ZEB1/Ngn3 signaling is critical for CSC pool expansion by enhancing the frequency of the SD population. Finally, we show that the expression of ZEB1 is increased in samples from breast cancer patients and is inversely correlated with NGN3 protein levels. Therefore, our results indicated that ZEB1/Ngn3 signaling may determine the replenishment of the breast CSC pool and promote tumor initiation.

Although ZEB1 is a well-characterized EMT regulator, several pieces of evidence suggest that it also contributes to the acquisition of CSC properties via a combination of genetic, epigenetic, and transcriptional mechanisms [31]. For example, ZEB1 interacts with HDAC components at the E-cadherin promoter in either a miR-200-dependent [32] or miR-200-independent manner [27], thus leading to induction of a mesenchymal-like phenotype and to increased tumorigenic potential. These findings suggest that ZEB1 might control tumor stemness by influencing the EMT process. However, Zhang et al. have reported that ZEB1 affects CSC-associated properties, such as radioresistance, independently of its ability to induce the EMT program, thus suggesting that adoption of a mesenchymal phenotype is not necessarily related to tumor onset [20]. In the present study, an essential role for ZEB1 in tumor initiation and maintenance in vitro and in vivo was confirmed by deleting ZEB1 in pre-existing breast cancer cells (MDA-MB-231 and SUM-159). Together, these findings demonstrate that ZEB1 may exert different tumorigenic functions (i.e.,
A

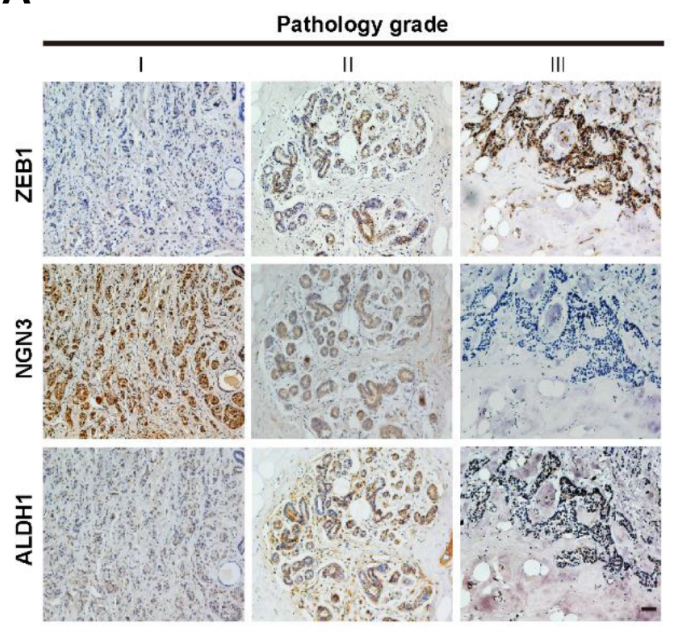

B

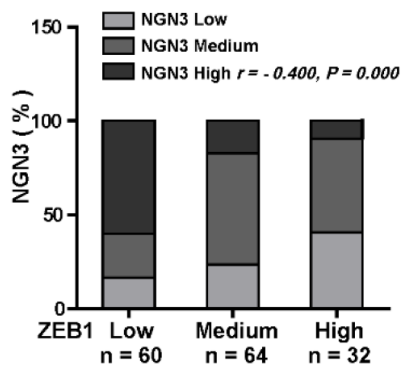

C

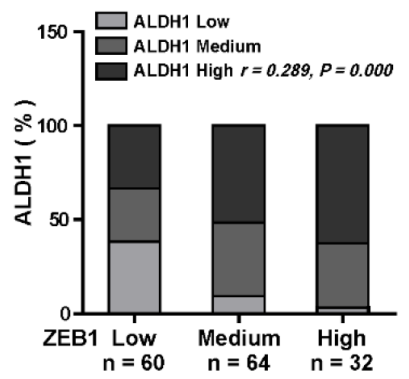

D

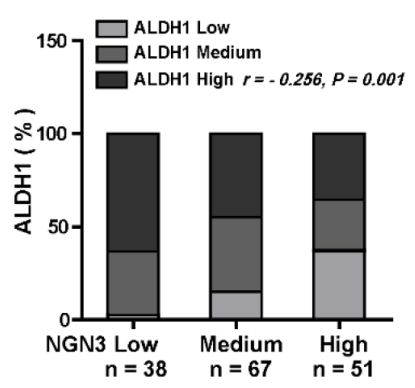

$\mathbf{E}$

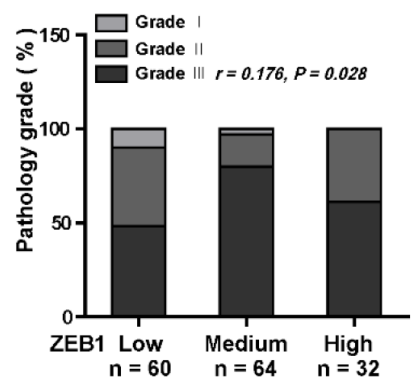

$\mathbf{F}$

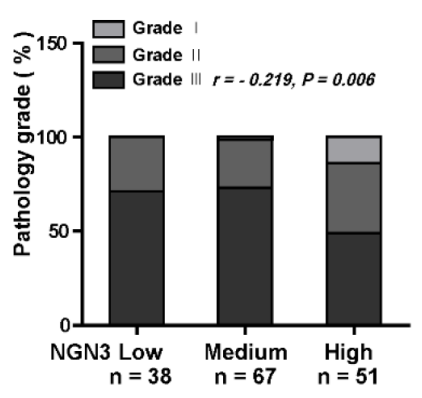

Figure 6: ZEB1 and NGN3 protein expression levels are inversely correlated in human breast cancer. (A) Representative images of immunohistochemical staining of ZEB1, NGN3, and ALDH1 in serial sections of the same tumor from three cases. Scale bars, $50 \mu \mathrm{m}$. (B) The expression score for NGN3 indicates a negative correlation with ZEB1 expression in the 156 human breast cancer samples analyzed. (C) The expression score for ALDH1 indicates a positive correlation with ZEB1 expression. (D) The expression score for ALDH1 indicates a negative correlation with NGN3 expression. (E) The expression of ZEB1 is positively correlated with the histological grades of breast cancer. (F) The expression of NGN3 is negatively correlated with the histological grades of breast cancer. All data were analyzed by Spearman's rank correction test. 
stemness maintenance and EMT) that are not necessarily interrelated.

Past studies of ZEB1 transcriptional activity were mostly focused on its impact within the EMT gene network, such as downregulation of epithelial cell markers (E-cadherin, PATJ, Crumbs3) and of some miR-200 family members that control epithelialmesenchymal specification, and upregulation of mesenchymal markers (v.g. vimentin, N-cadherin, and matrix metalloproteinases [33]. On the other hand, ZEB1 has been shown to affect stemness features indirectly, through transcriptional repression of miRNAs such as miR-200 and miR-203 [18]. Here, we identified Ngn3 as a direct ZEB1 target that mediates its effects on CSC maintenance and replenishment. NGN3 is a basic helixloop-helix transcription factor required for controlling cell fate differentiation in multipotent progenitor cells during embryogenesis. For example, during steady state spermatogenesis, $\mathrm{Ngn} 3$ expression marks a transition from strong spermatogonial stem cell potential to committed transit-amplifying cells that normally proliferate and differentiate [34]. Ngn3 also acts as a genetic switch in pluripotent pancreatic progenitor cells, by specifying an endocrine cell fate [35]. The importance of Ngn3 in the control of endocrine cell differentiation can also be observed in the stomach and intestine [36]. Notably, Lee et al. have reported that $\mathrm{Ngn3}^{-/-}$mice display intestinal metaplasia (IM) of the gastric epithelium [37]. Given that IM is an important risk factor for gastric cancer and an inevitable stage in gastrocarcinogenesis [38], these observations suggest an inhibitory effect of $\mathrm{Ngn} 3$ on the appearance of CSC characteristics that is in agreement with our data from in vitro and in vivo breast cancer models (Supplementary Figure 10 and 11). Thus, downregulation of $\mathrm{Ngn} 3$ expression is at least partially involved in the mechanism by which ZEB1 promotes breast cancer cell stemness and tumor initiation and progression.

Although mainly recognized by its silencing effects on epithelial gene expression, ZEB1 can also mediate direct transcriptional activation of target genes, depending on the nature of the co-factors recruited [39, 40]. Gene silencing has been shown to occur during ZEB1 complexation with PC2-CtBP-LSD1-LCoR, or with the chromatin-remodeling protein BRG [41]; recruitment of Smad3-p300-P/CAF, in contrast, results in transcriptional activation [42]. Here we provide an alternative mechanism for ZEB1/Ngn3-mediated stemness acquisition in breast cancer cells that involves methylation and deacetylation of the Ngn3 promoter. Namely, upon ZEB1 interaction with DNMT3B and HDAC1, the ensuing promoter hypermethylation and histone deacetylation result in repression of $\mathrm{Ngn} 3$ expression, an effect readily reversed by inhibiting DNA methylation with AZA and histone deacetylation with TSA. Accordingly, by examining 156 primary breast cancer specimens, we confirmed that ZEB1 is overexpressed in cancer tissues, and its expression is inversely correlated with that of NGN3. Thus, dysregulation of Ngn3 may provide a mechanistic link between the ectopic expression of ZEB1 and the ontogeny of aggressive breast cancer. These results were further supported by our analysis of cell division variants (symmetric versus asymmetric) in CSCs, which evidenced the critical role of ZEB1/Ngn3 signaling in replenishing the breast CSC pool and promoting tumorigenesis. Similarly to our own conclusions regarding ZEB1, the polarity of cell division has been shown to be affected by p53 in murine mammary stem cells; in this model, p53 loss leads to uniform NUMB redistribution in the stem cell undergoing mitosis, enhances mammospheres' replication potential, and increases the rate of SD [43]. Although in such study the underlying mechanism remained undefined, a recent study implicated ZEB1 as a direct transcriptional target of p53 [44]; thus we believe that ZEB1 signaling may be involved.

In summary, our study uncovered a key role for ZEB1 in the establishment of CSC properties and in promoting tumor initiation by breast CSCs. Since ZEB1 may affect different steps in the tumorigenic process, more detailed studies are needed to elucidate its possible contribution to tumor initiation and expansion. In addition, given that ZEB1 downregulation parallels metastatic colonization $[45,46]$, its possible contribution to the metastatic process should also be addressed.

\section{MATERIALS AND METHODS}

\section{Cell culture and transfection}

Human breast cancer cell lines were maintained in DMEM (SUM-159) and RPMI 1640 (MDA-MB-231) supplemented with $10 \%$ FBS, 100 IU penicillin, and $100 \mathrm{mg} / \mathrm{mL}$ streptomycin. Cells were transfected using Lipofectamine 2000 (Invitrogen, California, USA) according to the manufacturer's protocol.

\section{Plasmid construction}

The human cDNA fragment encoding full-length ZEB1 and Ngn3 was prepared by PCR and cloned into pLV-EF1-MCS-IRES-Bsd (Biosettia, San Diego, USA). The lentiviral-based vector pLV-H1-EF1 $\alpha$-puro (Biosettia, San Diego, USA) was used to express shRNAs in breast cancer cells. The human Ngn3 full-length and truncated promoter sequences were obtained by PCR from human genomic DNA and cloned into the pGL3-basic vector (Promega, Wisconsin, USA). Primer sequences are listed in Supplementary Data.

\section{Generation of lentiviruses}

Lentiviruses were generated by transfecting subconfluent HEK293T cells with lentiviral vectors and 
packaging plasmids via calcium phosphate transfection. Viral supernatants were collected $48 \mathrm{~h}$ after transfection, resuspended, and filtered through $0.45 \mu \mathrm{m}$ filters (Millipore, Massachusetts, USA). MDA-MB-231 or SUM-159 cells were transduced with lentivirus-containing medium and selected with antibiotic. After one week, cell pools were obtained and expanded.

\section{RNA extraction and quantitative RT-PCR}

Total RNA $(0.5 \mu \mathrm{g})$ from each sample was collected using TRIzol reagent (Invitrogen, California, USA), and first-strand cDNA synthesis was performed using M-MLV Reverse Transcriptase (Takara, Tokyo, Japan). The specific products were amplified by quantitative PCR using a TransStart Green Q-PCR SuperMix Kit (TransGen, Beijing, China). GAPDH was used as a normalization control. Primer sequences are listed in Supplementary Data.

\section{Luciferase assay}

Cells were co-transfected with full-length or truncated human Ngn3 promoters and ZEB1 expression plasmid in 24-well plates. Lysates were prepared $36 \mathrm{~h}$ after transfection, and luciferase activity was measured using the Dual-Luciferase Reporter Assay System (Promega, Wisconsin, USA) according to the manufacturer's protocol. Luciferase activity was normalized to Renilla luciferase activity.

\section{Immunoblotting assay}

The preparation of total cell extracts and immunoblotting with appropriate antibodies (indicated in Supplementary Data) were performed as previously described [47]. Labeled proteins were visualized with an ECL chemiluminescence kit (Millipore, Massachusetts, USA).

\section{Tumorsphere assay}

Single-cell suspensions were prepared in sphereculturing medium (Stemcell Technologies) and seeded in 24-well ultra-low attachment plates (Corning) at 1,000 cells/well. The number of wells with spheres was recorded on day 14 after culturing. Tumorsphere formation was monitored using an inverted Leica microscope fitted with a camera. Sphere numbers and diameters were imaged and quantified in $>5$ fields per sample.

\section{Flow cytometry}

The ALDEFLUOR assay (Stemcell Technologies) was performed according to the manufacturer's guidelines to identify cells with high ALDH activity. Cells were incubated for 40 minutes at $37{ }^{\circ} \mathrm{C}$ in the presence or absence of the ALDH inhibitor diethylaminobenzaldehyde. To identify the CD44 ${ }^{+} \mathrm{CD} 24^{-}$population, CD44-APC and CD24-PE primary antibodies (BD, USA) were incubated with single cells in PBS containing 2\% FBS for 30 minutes at $4^{\circ} \mathrm{C}$. Then, cells were washed twice with PBS, resuspended in $1 \mathrm{~mL}$ PBS, and kept on ice until FACS analysis. To identify the side population (SP) and nonside population fractions, cells were trypsinized and suspended at a concentration of $1 \times 10^{6}$ cells $/ \mathrm{mL}$ in PBS containing 2\% FBS. Hoechst 33342 dye (Sigma-Aldrich, Vienna, Austria) was added at a final concentration of 5 $\mu \mathrm{g} / \mathrm{mL}$ in the presence or absence of $100 \mu \mathrm{M}$ verapamil (Sigma-Aldrich), and the cells were incubated at $37^{\circ} \mathrm{C}$ for $90 \mathrm{~min}$ with intermittent shaking every $15 \mathrm{~min}$. The cells were washed twice with PBS and resuspended in 1 $\mathrm{mL}$ PBS with $1 \mu \mathrm{g} / \mathrm{mL}$ propidium iodide and kept on ice until FACS analysis. Cell analyses were carried out with a FACSAria instrument (BD, USA).

\section{Methylation assays}

DNA was extracted from breast cancer cells and processed for bisulfite treatment (Qiagen, Hilden, Germany). Bisulfite-treated DNA was then used to examine the methylation status of the $\mathrm{CpG}$ islands in the Ngn3 promoter, using Bisulfite-Sequencing PCR (BSP) according to the manufacturer's protocol (Roche, Basel, Switzerland). Primer sequences are listed in Supplementary Data.

\section{Immunoprecipitation assay}

Cell lysates were incubated with specific antibodies and Protein G agarose beads (Invitrogen, California, USA) at $4{ }^{\circ} \mathrm{C}$ overnight, then washed three times with a buffer containing $50 \mathrm{mM}$ Tris ( $\mathrm{pH}$ 7.5), $100 \mathrm{mM} \mathrm{NaCl}, 7.5 \mathrm{mM}$ EGTA, and $0.1 \%$ Triton X-100. The antibodies used for immunoprecipitation are shown in Supplementary Data.

\section{Chromatin immunoprecipitation}

ChIP assays were performed using an EZ-ChIP kit (Millipore, Massachusetts, USA) according to the manufacturer's instructions. The antibodies used in these experiments are shown in Supplementary Data. The fragments of human $\mathrm{Ngn} 3$ promoter containing the $\mathrm{E}_{2}$-box 1, $E_{2}$-box 2 and $E_{2}$-box 3 elements in immunoprecipitates were amplified by quantitative PCR. Primer sequences are listed in Supplementary Data.

\section{Tissue samples}

A total of 156 human breast cancer specimens were obtained from the General Hospital of the People's Liberation Army (PLAGH, Beijing, China). All patients had histologically confirmed invasive ductal carcinoma of the breast and were recruited by the same department. This 
study was approved by the institutional ethics committees at PLAGH and the Medical College of Nankai University.

\section{Immunohistochemical analysis}

Immunohistochemical analysis of paraffinembedded sections was performed using an Envision Kit (Dako, Denmark) according to the manufacturer's protocol. Sections were boiled in retrieval solution to expose antigens. Specific antibodies (see Supplementary Data) were applied to the sections. Slides were counterstained with hematoxylin, dehydrated, and mounted. Immunostaining was independently evaluated by 2 pathologists.

\section{Cell division assay}

CD $44^{+}$CD24- cells were treated with $20 \mathrm{mM}$ blebbistatin (Selleck Chemicals, USA) for 48 hours in suspension culture and fixed for 20 minutes in $10 \%$ neutral buffered formalin at $-20^{\circ} \mathrm{C}$. Fixed cells were blocked for 1.5 hours with $5 \%$ goat serum and then incubated with anti-Numb and anti-CD44 primary antibodies diluted in TBST (containing $0.1 \%$ Tween 20 and 5\% BSA) overnight at $4^{\circ} \mathrm{C}$. Then, cells were washed 3 times with TBST at RT, incubated with secondary antibodies for 1 hour, then washed 3 times at RT. The secondary antibodies were DyLight 488 goat anti-mouse and DyLight 594 goat antirabbit. Cell nuclei were counterstained and mounted with Prolong Gold Antifade Reagent with DAPI (Molecular Probes) overnight at RT.

\section{Tumor xenograft experiments}

All experimental procedures involving animals were performed according to the institutional ethical guidelines for animal experiments and approved by the Ethics Committee for Animal Use at the Medical College of Nankai University. Briefly, cells were collected and suspended at different concentrations $\left(1.0 \times 10^{7}, 5.0 \times 10^{6}\right.$, $2.5 \times 10^{6}, 1.25 \times 10^{6}$, and $6.25 \times 10^{5}$ cells $/ \mathrm{mL}$ ) in $200 \mu \mathrm{L} \mathrm{PBS}$, and then injected into the mammary fat pads of female BALB/c nude mice. After 15 days, mice were euthanized, and the tumor tissues were processed for detection of the CD $44^{+}$CD24- population and ALDH activity and sectioned for histological evaluation. For limited dilution assays, data analysis was performed using the publicly available ELDA (extreme limiting dilution analysis for comparing depleted and enriched populations in stem cell and other assays) software [48].

\section{Isolation of primary tumor cells}

Tumors were surgically removed from anesthetized mice and minced with a scalpel in RPMI medium containing trypsin $(1 \mathrm{mg} / \mathrm{mL})$ and collagenase I $(3 \mathrm{mg}$ / $\mathrm{mL}) ; 2 \%$ FBS was added, and the tissue fragments were incubated for 45 minutes in a shaker $\left(37^{\circ} \mathrm{C}, 90 \mathrm{rpm}\right)$. The dissociated cells were filtered through $40 \mu \mathrm{m}$ cell strainers (BD, USA) and concentrated by centrifugation at 1,500 rpm for 15 minutes at RT. Cells were washed with $50 \mathrm{~mL}$ volumes of PBS until the supernatant was clear of red blood cells.

\section{Statistical analysis}

Statistical analyses were performed using SPSS 13.0 software (SPSS, Chicago, IL, USA). Data are presented as the means $\pm \mathrm{SD}$ and represent three independent experiments. Spearman's rank correlation test was used to analyze the correlation of gene expression in tissue samples. One-way analysis of variance (ANOVA) was used to compare means between treatment groups. Where appropriate, Student's $t$-test for unpaired observations was applied. A $P$-value $<0.05$ was considered significant.

\section{ACKNOWLEDGMENTS}

This work was supported by grants from the International S\&T Cooperation Program of China (No. 2015DFA30420), and the National Natural Science Foundation of China (No. 81472545; No. 31428013; No. 81372386).

\section{CONFLICTS OF INTEREST}

The authors have no conflicts of interest.

\section{REFERENCES}

1. Reya T, Morrison SJ, Clarke MF, Weissman IL. Stem cells, cancer, and cancer stem cells. Nature. 2001; 414:105-11.

2. Visvader JE, Lindeman GJ. Cancer stem cells in solid tumours: accumulating evidence and unresolved questions. Nat Rev Cancer. 2008; 8:755-68.

3. Brabletz T, Jung A, Spaderna S, Hlubek F, Kirchner T. Opinion: migrating cancer stem cells - an integrated concept of malignant tumour progression. Nat Rev Cancer. 2005; 5:744-49.

4. Lasorella A, Benezra R, Iavarone A. The ID proteins: master regulators of cancer stem cells and tumour aggressiveness. Nat Rev Cancer. 2014; 14:77-91.

5. Lotem J, Sachs L. Epigenetics and the plasticity of differentiation in normal and cancer stem cells. Oncogene. 2006; 25:7663-72.

6. Marquardt JU, Factor VM, Thorgeirsson SS. Epigenetic regulation of cancer stem cells in liver cancer: current concepts and clinical implications. J Hepatol. 2010; 53:568-77.

7. Torres CM, Biran A, Burney MJ, Patel H, Henser-Brownhill T, Cohen AS, Li Y, Ben-Hamo R, Nye E, Spencer-Dene B, Chakravarty P, Efroni S, Matthews N, et al. The linker 
histone H1.0 generates epigenetic and functional intratumor heterogeneity. Science. 2016; 353:353.

8. Williams SE, Beronja S, Pasolli HA, Fuchs E. Asymmetric cell divisions promote Notch-dependent epidermal differentiation. Nature. 2011; 470:353-58.

9. Harandi OF, Ambros VR. Control of stem cell self-renewal and differentiation by the heterochronic genes and the cellular asymmetry machinery in Caenorhabditis elegans. Proc Natl Acad Sci USA. 2015; 112:E287-96.

10. Higashi Y, Moribe H, Takagi T, Sekido R, Kawakami K, Kikutani H, Kondoh H. Impairment of T cell development in deltaEF1 mutant mice. J Exp Med. 1997; 185:1467-79.

11. Takagi T, Moribe H, Kondoh H, Higashi Y. DeltaEF1, a zinc finger and homeodomain transcription factor, is required for skeleton patterning in multiple lineages. Development. 1998; 125:21-31.

12. Hasuwa H, Ueda J, Ikawa M, Okabe M. miR-200b and miR-429 function in mouse ovulation and are essential for female fertility. Science. 2013; 341:71-73.

13. Eger A, Aigner K, Sonderegger S, Dampier B, Oehler S, Schreiber M, Berx G, Cano A, Beug H, Foisner R. DeltaEF1 is a transcriptional repressor of E-cadherin and regulates epithelial plasticity in breast cancer cells. Oncogene. 2005; 24:2375-85.

14. Graham TR, Zhau HE, Odero-Marah VA, Osunkoya AO, Kimbro KS, Tighiouart M, Liu T, Simons JW, O'Regan RM. Insulin-like growth factor-I-dependent up-regulation of ZEB1 drives epithelial-to-mesenchymal transition in human prostate cancer cells. Cancer Res. 2008; 68:2479-88.

15. Spaderna S, Schmalhofer O, Wahlbuhl M, Dimmler A, Bauer K, Sultan A, Hlubek F, Jung A, Strand D, Eger A, Kirchner T, Behrens J, Brabletz T. The transcriptional repressor ZEB1 promotes metastasis and loss of cell polarity in cancer. Cancer Res. 2008; 68:537-44.

16. Wellner U, Brabletz T, Keck T. ZEB1 in Pancreatic Cancer. Cancers (Basel). 2010; 2:1617-28.

17. Aigner K, Dampier B, Descovich L, Mikula M, Sultan A, Schreiber M, Mikulits W, Brabletz T, Strand D, Obrist P, Sommergruber W, Schweifer N, Wernitznig A, et al. The transcription factor ZEB1 (deltaEF1) promotes tumour cell dedifferentiation by repressing master regulators of epithelial polarity. Oncogene. 2007; 26:6979-88.

18. Wellner U, Schubert J, Burk UC, Schmalhofer O, Zhu F, Sonntag A, Waldvogel B, Vannier C, Darling D, zur Hausen A, Brunton VG, Morton J, Sansom O, et al. The EMTactivator ZEB1 promotes tumorigenicity by repressing stemness-inhibiting microRNAs. Nat Cell Biol. 2009; 11:1487-95.

19. Siebzehnrubl FA, Silver DJ, Tugertimur B, Deleyrolle LP, Siebzehnrubl D, Sarkisian MR, Devers KG, Yachnis AT, Kupper MD, Neal D, Nabilsi NH, Kladde MP, Suslov O, et al. The ZEB1 pathway links glioblastoma initiation, invasion and chemoresistance. EMBO Mol Med. 2013; 5:1196-212.

20. Zhang P, Wei Y, Wang L, Debeb BG, Yuan Y, Zhang J, Yuan J, Wang M, Chen D, Sun Y, Woodward WA, Liu Y, Dean DC, et al. ATM-mediated stabilization of ZEB1 promotes DNA damage response and radioresistance through CHK1. Nat Cell Biol. 2014; 16:864-75.

21. Zhang Y, Toy KA, Kleer CG. Metaplastic breast carcinomas are enriched in markers of tumor-initiating cells and epithelial to mesenchymal transition. Mod Pathol. 2012; 25:178-84.

22. Liu Y, Clem B, Zuba-Surma EK, El-Naggar S, Telang S, Jenson AB, Wang Y, Shao H, Ratajczak MZ, Chesney J, Dean DC. Mouse fibroblasts lacking RB1 function form spheres and undergo reprogramming to a cancer stem cell phenotype. Cell Stem Cell. 2009; 4:336-47.

23. Brabletz S, Bajdak K, Meidhof S, Burk U, Niedermann G, Firat E, Wellner U, Dimmler A, Faller G, Schubert J, Brabletz T. The ZEB1/miR-200 feedback loop controls Notch signalling in cancer cells. EMBO J. 2011; 30:770-82.

24. Chaffer CL, Marjanovic ND, Lee T, Bell G, Kleer CG, Reinhardt F, D'Alessio AC, Young RA, Weinberg RA. Poised chromatin at the ZEB1 promoter enables breast cancer cell plasticity and enhances tumorigenicity. Cell. 2013; 154:61-74.

25. Chao CH, Chang CC, Wu MJ, Ko HW, Wang D, Hung MC, Yang JY, Chang CJ. MicroRNA-205 signaling regulates mammary stem cell fate and tumorigenesis. J Clin Invest. 2014; 124:3093-106.

26. Schliekelman MJ, Gibbons DL, Faca VM, Creighton CJ, Rizvi ZH, Zhang Q, Wong $\mathrm{CH}$, Wang $\mathrm{H}$, Ungewiss $\mathrm{C}$, Ahn YH, Shin DH, Kurie JM, Hanash SM. Targets of the tumor suppressor miR-200 in regulation of the epithelialmesenchymal transition in cancer. Cancer Res. 2011; 71:7670-82.

27. Aghdassi A, Sendler M, Guenther A, Mayerle J, Behn CO, Heidecke CD, Friess H, Büchler M, Evert M, Lerch MM, Weiss FU. Recruitment of histone deacetylases HDAC1 and HDAC2 by the transcriptional repressor ZEB1 downregulates E-cadherin expression in pancreatic cancer. Gut. 2012; 61:439-48.

28. Klein AM, Nakagawa T, Ichikawa R, Yoshida S, Simons BD. Mouse germ line stem cells undergo rapid and stochastic turnover. Cell Stem Cell. 2010; 7:214-24.

29. Shankar S, Srivastava RK. Histone deacetylase inhibitors: mechanisms and clinical significance in cancer: HDAC inhibitor-induced apoptosis. Adv Exp Med Biol. 2008; 615:261-98.

30. Sekido R, Takagi T, Okanami M, Moribe H, Yamamura M, Higashi Y, Kondoh H. Organization of the gene encoding transcriptional repressor deltaEF1 and cross-species conservation of its domains. Gene. 1996; 173:227-32. 
31. Scheel C, Weinberg RA. Cancer stem cells and epithelialmesenchymal transition: concepts and molecular links. Semin Cancer Biol. 2012; 22:396-403.

32. Shimono Y, Zabala M, Cho RW, Lobo N, Dalerba P, Qian D, Diehn M, Liu H, Panula SP, Chiao E, Dirbas FM, Somlo G, Pera RA, et al. Downregulation of miRNA-200c links breast cancer stem cells with normal stem cells. Cell. 2009; 138:592-603.

33. Castilla MA, Moreno-Bueno G, Romero-Pérez L, Van De Vijver K, Biscuola M, López-García MÁ, Prat J, MatíasGuiu X, Cano A, Oliva E, Palacios J. Micro-RNA signature of the epithelial-mesenchymal transition in endometrial carcinosarcoma. J Pathol. 2011; 223:72-80.

34. Tang F, Yao X, Zhu H, Mu H, Niu Z, Yu M, Yang C, Peng S, Li G, Hua J. Expression pattern of Ngn3 in dairy goat testis and its function in promoting meiosis by upregulating Stra8. Cell Prolif. 2014; 47:38-47.

35. Liu H, Yang H, Zhu D, Sui X, Li J, Liang Z, Xu L, Chen Z, Yao A, Zhang L, Zhang X, Yi X, Liu M, et al. Systematically labeling developmental stage-specific genes for the study of pancreatic $\beta$-cell differentiation from human embryonic stem cells. Cell Res. 2014; 24:1181-200.

36. Jenny M, Uhl C, Roche C, Duluc I, Guillermin V, Guillemot F, Jensen J, Kedinger M, Gradwohl G. Neurogenin3 is differentially required for endocrine cell fate specification in the intestinal and gastric epithelium. EMBO J. 2002; 21:6338-47.

37. Lee CS, Perreault N, Brestelli JE, Kaestner KH. Neurogenin 3 is essential for the proper specification of gastric enteroendocrine cells and the maintenance of gastric epithelial cell identity. Genes Dev. 2002; 16:1488-97.

38. Busuttil RA, Zapparoli GV, Haupt S, Fennell C, Wong SQ, Pang JM, Takeno EA, Mitchell C, Di Costanzo N, Fox S, Haupt Y, Dobrovic A, Boussioutas A. Role of p53 in the progression of gastric cancer. Oncotarget. 2014; 5:1201626. doi: 10.18632/oncotarget.2434.

39. Lehmann W, Mossmann D, Kleemann J, Mock K, Meisinger C, Brummer T, Herr R, Brabletz S, Stemmler MP, Brabletz T. ZEB1 turns into a transcriptional activator by interacting with YAP1 in aggressive cancer types. Nat Commun. 2016; 7:10498.
40. Kan JY, Yen MC, Wang JY, Wu DC, Chiu YJ, Ho YW, Kuo PL. Nesfatin-1/Nucleobindin-2 enhances cell migration, invasion, and epithelial-mesenchymal transition via LKB1/AMPK/TORC1/ZEB1 pathways in colon cancer. Oncotarget. 2016; 7:31336-49. doi: 10.18632/ oncotarget.9140.

41. Sánchez-Tilló E, Lázaro A, Torrent R, Cuatrecasas M, Vaquero EC, Castells A, Engel P, Postigo A. ZEB1 represses E-cadherin and induces an EMT by recruiting the SWI/SNF chromatin-remodeling protein BRG1. Oncogene. 2010; 29:3490-500.

42. Nakahata S, Yamazaki S, Nakauchi H, Morishita K. Downregulation of ZEB1 and overexpression of Smad7 contribute to resistance to TGF-betal-mediated growth suppression in adult T-cell leukemia/lymphoma. Oncogene. 2010; 29:4157-69.

43. Tosoni D, Zecchini S, Coazzoli M, Colaluca I, Mazzarol G, Rubio A, Caccia M, Villa E, Zilian O, Di Fiore PP, Pece $\mathrm{S}$. The Numb/p53 circuitry couples replicative self-renewal and tumor suppression in mammary epithelial cells. J Cell Biol. 2015; 211:845-62.

44. Dong P, Karaayvaz M, Jia N, Kaneuchi M, Hamada J, Watari H, Sudo S, Ju J, Sakuragi N. Mutant p53 gain-offunction induces epithelial-mesenchymal transition through modulation of the miR-130b-ZEB1 axis. Oncogene. 2013; 32:3286-95.

45. Morrison CD, Parvani JG, Schiemann WP. The relevance of the TGF- $\beta$ Paradox to EMT-MET programs. Cancer Lett. 2013; 341:30-40.

46. Brabletz T. EMT and MET in metastasis: where are the cancer stem cells? Cancer Cell. 2012; 22:699-701.

47. Yang S, Du J, Wang Z, Yuan W, Qiao Y, Zhang M, Zhang J, Gao S, Yin J, Sun B, Zhu T. BMP-6 promotes E-cadherin expression through repressing deltaEF1 in breast cancer cells. BMC Cancer. 2007; 7:211.

48. Hu Y, Smyth GK. ELDA: extreme limiting dilution analysis for comparing depleted and enriched populations in stem cell and other assays. J Immunol Methods. 2009; 347:70-78. 